DIW BERLIN

Discussion Papers

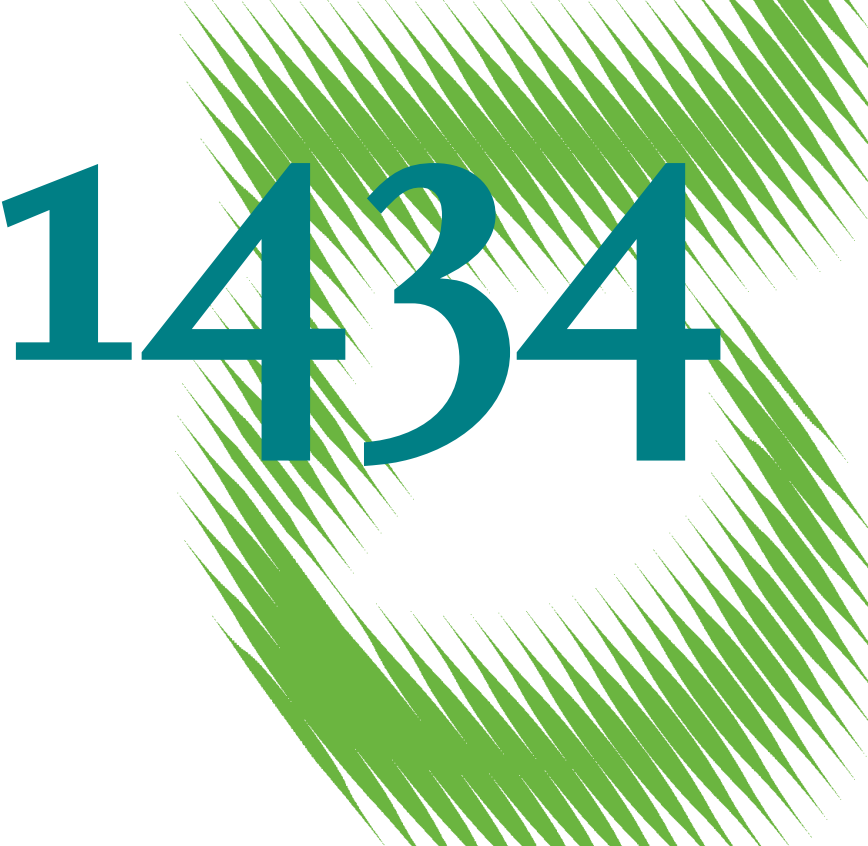

Increasing Block Tariffs in the Water Sector - An Interpretation in Terms of Social Preferences 
Opinions expressed in this paper are those of the author(s) and do not necessarily reflect views of the institute.

IMPRESSUM

(C) DIW Berlin, 2014

DIW Berlin

German Institute for Economic Research

Mohrenstr. 58

10117 Berlin

Tel. +49 (30) $89789-0$

Fax +49 (30) $89789-200$

http://www.diw.de

ISSN electronic edition 1619-4535

Papers can be downloaded free of charge from the DIW Berlin website:

http://www.diw.de/discussionpapers

Discussion Papers of DIW Berlin are indexed in RePEc and SSRN:

http://ideas.repec.org/s/diw/diwwpp.html

http://www.ssrn.com/link/DIW-Berlin-German-Inst-Econ-Res.html 


\title{
Increasing Block Tariffs in the Water Sector - An Interpretation in Terms of Social Preferences
}

\author{
by \\ Georg Meran* and Christian von HirschHausen
}

September 2014

Many developing countries around the world apply progressive water tariffs, often structured in the form of discretely increasing block tariffs (IBTs). These tariffs have been criticized in the welfare economic literature due to their perceived inefficiency: many of the prices charged under IBTs do not correspond to marginal costs and thus violate the principle of allocative efficiency. In this paper we explore an alternative interpretation of the widespread use of IBTs, in terms of social preferences and fairness considerations. For this, we rely on an extension of the Fehr and Schmidt (1999) utility function, including inequality aversion, to which we add another parameter representing a preference for redistribution, which reflects a societal preference to correct for income difference perceived as unfair. In addition, the paper also includes household size in the analysis, finding that as poor households are on average larger (in per capita terms), a simple IBT tariff disregarding household size may not be

${ }^{*}$ Georg Meran is with Berlin University of Technology (e-mail: g.meran@tu-berlin.de) and Christian von Hirschhausen is with Berlin University of Technology and DIW Berlin (e-mail: cvh@wip.tu-berlin.de). We thank Dorothea Kübler from WZB Berlin for valuable comments. The usual disclaimer applies. 
"fair" at all. We conclude on a methodological note on the importance of addressing allocative and distributional issues simultaneously.

Keywords: water, tariffication, prices, fairness, distribution, institutions (JEL: L51, L95, H21, D40).

\section{Introduction}

The pricing of water is often dominated by political and socio-economic influences, and it has often been criticized by economists for being "inefficient". This applies particularly to a pricing scheme that is often observed in the water sector, in particular in a developing context: increasing block tariffs (IBTs), where the marginal price for water increases with the amount of water consumed (Whittington, 2003). In general, these are discrete blocks, whereas the more general form, a continuous block tariff, is referred to as a "progressive" tariff. Thus, Whittington (2003) and Boland and Whittington (2000) report about the wide-spread use of IBTs, amongst other regions in Asia, and have also criticzed it. As an alternative, they have proposed a 'Uniform Price with Rebate' (UPR) which is a two-part tariff where the volumetric charge is equal to marginal costs and a fixed monthly credit (fixed amount subtracted from the bill). ${ }^{1}$

The main criticism in the literature is that IBTs will not lead to "socially efficient" outcomes, mainly allocative efficiency, where prices should be equal (or at least strongly related) to marginal costs. Thus, the "second-best" literature derives welfare-optimal non-uniform prices from maximizing total consumer surplus subject to incentive compatibility constraints and a zero-profit condition; this generally leads to general Ramsey-rules, which are the opposite of IBTs. An example is Goldman, Leland, and Sibley (1984) who also take into account income effects, and the optimal taxation reasoning initially developed by Mirrlees $(1971,1976)$ : both argue that

\footnotetext{
${ }^{1}$ The reason for marginal cost pricing follows from their assumption that, contrary to ours, average costs are below marginal costs, i.e. marginal costs are increasing. As a result, charging a water price equal to marginal costs does not lead to losses.
} 
pricing schemes no longer have a Ramsey interpretation of minimizing the deviation from the first best allocation (marginal cost pricing) but also have to provide for distributional purposes if income effects are taken into account. Mirrlees' optimal taxation scheme requires a decrease of the marginal rate for high incomes to be welfare optimal; Diamond and Saez (2011) summarize the debate on the marginal tax rates. Sharkey and Sibley (1993) develop optimal non-linear pricing schemes for an arbitrary number of customer types and general cost functions; the "benevolent" regulator can define welfare weights which vary over the set of customer types; in this case, the marginal price can be below marginal cost if welfare weights increase with type (Sharkey and Sibley, 1993, p. 228). Cowen and Cowen (1998) propose a radical form of price differentiation: the unregulated monopoly, that maximizes social surplus by maximizing producer rent, at the expense of consumer rent. This tariff, too, deviates largely from the range of IBTs observed in practice. Another criticism comes from Dahan and Nisan (2007) who insist on the unintended consequences of increasing block tariffs in urban water: since larger households, that are generally poorer, consume more water than smaller households, they are charged a higher price for water. This erodes the effectiveness of increasing block tariffs.

On the other hand, the criticism of IBTs has been challenged, in turn, by authors insisting on the specifics of water as a subsistence good: the optimal exclusion of users, some argue, may not take into account the vital importance of water for survival and a decent life. Thus, Diakite, et al. (2009) have developed welfare optimal non-uniform pricing schemes for the water supply in Cote d'Ivoire under the provision that poor households have access to a minimum volume of water for a volumetric price of zero and a fixed fee set according to their willingness to pay for this amount of water ${ }^{2}$ Their model is a supplemented application of nonlinear pricing developed by Wilson (1992). This type of models dispenses with the usual incentive compatibility constraints introduced in the second best literature by developing the

\footnotetext{
${ }^{2}$ The simulation experiment yields a minimum volume of water of $106 \mathrm{~cm} /$ year for a fixed fee of 64 USD/year. Strictly speaking, their approach cannot exclude that the minimum volume of water lies under the lifeline; this is due to their methodology to determine the minimum volume of water solely on the basis of willingness to pay data.
} 
concept of a demand profile which is a disaggregated form of a demand function. ${ }^{3}$ It is known from this literature and the literature of optimal taxation that optimal marginal tariff functions are often non-monotonic. Diakite, Semenov and Thomas (2009) derive a quantity-dependent continuous marginal price function that exhibits quantity discounts leading to a minimum price. Beyond this point marginal prices increase up to a peak to decrease again to marginal costs. However specific to the water sector, this pricing rule is neither transparent nor practical to handle, which reduces the chances of being accepted and implemented.

In this paper, we explore an interpretation of the widespread use of IBTs in the water sector, relying on recent advances in the theory of social preferences and welfare considerations. The main contribution of our paper is to challenge the conventional wisdom that increasing block tariffs are really inefficient, as a large part of the literature contends. Approaching the issue through the lens of fairness considerations, we identify another interpretation of progressive or increasing block tariffs: it's perceived fairness which may assure its social acceptability and, hence, its enforceability. Today, we know from the theoretical and the experimental literature that fairness considerations contribute significantly to the social acceptance of tariffs, and to sustainable economic development altogether. Thus, it would not be surprising to find that water tariffs include a fairness component, and that this implies a different tariff structure. This paper, therefore, builds on models of fairness and (optimal) equality, such as proposed, amongst others, by Fehr and Schmidt (1999), or Bolton and Ockenfels (2000), to which we add a parameter for redistributional preference. Issues of fairness and redistribution are not new in the literature, but they have not been broadly applied to the water sector thus far. The paper sets out a model developing on the recent literature on fairness and equality that - in addition - takes into account the specifics of the water sector, including the potentially important role of household size. Our approach is not normative, but positive: rather than

\footnotetext{
${ }^{3}$ Local infrastructure monopolies often have a large stock of household related data which allows them to build up a demand profile of water consumption. Utilizing the demand profile approach one can derive a general Ramsey-Rule that leads to a non-linear pricing scheme.
} 
to support or to criticize IBTs, we seek a possible explanation of a tariff structure that dominates the real world. Our finding indeed supports the idea that IBTs might be efficient in a certain sense, because they may express societys preference for redistribution that is absent from other explanations; however, we do not derive normative policy implications, e.g. in the sense that regulators should adopt these tariffs more strongly.

The rest of the paper is structured in the following way: the next section sets up notions of social preferences and of "fair" tariffs, being based on utility functions with inequality aversion and redistributional preferences a la Fehr and Schmidt (1999). We first derive the case of two customers and calculate what this might imply in terms of tariff setting. In doing so, we take into account the specifics of the water sector, where it is commonly agreed that consumers should receive a certain amount of water independently of income or marginal willingness to pay: the Stone-Geary utility function allocates a subsistence amount of water to each household. In a two household-two incomes setting, we find that IBTs can be interpreted as a solution that represents societal attitudes in terms of inequity aversion and redistributional preferences. Section 3 provides a generalization of this result, to the continuous case of progressive (water) tariffs. We find that the tariff function exhibits the relation between progressivity and the distributional preferences; if the distributional preferences of society are high, the tariff function is strongly progressive; if distributional preferences are fully absent, the tariff function is linear. The analytical model includes a feature that solves the information asymmetry between the price setting agency (regulator) and the consumers, through an incentive compatibility constraint; since this makes the analytics complicated, we provide some numerical examples to strengthen the intuition of the results.

Section 4 then includes an extension of the model taking into account the household size. In most developing and emerging countries that use IBTs, one observes in fact an inverse relation between income and household size, that is often ignored by the price setting agency. As poor households are on average larger (in per capita terms), a simple IBT tariff may not be "fair" at all. Our model extension explicitely takes 
into account household size and we fnd that this leads to a stronger progression of IBTs. The last section concludes on a methodological note on the importance of addressing allocative and distributional issues simultaneously.

\section{Social preferences and increasing block tariffs}

\subsection{Inequity aversion}

The very rational of increasing block tariffs is their alleged fairness. But the precise relation between fairness and the progressive structure of a tariff system is not as obvious as asserted. In the more applied literature the mere progressive structure is identified with fairness and environmental awareness, see the critical rerview in Boland and Whittington, (2000). The progressive tariff structure allegedly contributes to a desirable income redistribution. On the other hand, we know from the optimal tax literature that a fair income tax function that includes distributional goals is not necessarily progressive over the whole range of income. ${ }^{4}$ Instead, optimality may prescribe declining marginal tax rates as income rises. This feature can also occur in the case of non-linear water tariffs, such as in Diakite, et al.(2009). These results are derived from a social planner's perspective which does not account for the acceptability of tariff schemes. It is our contention that the construction of a tariff schedule has to take into account fairness consideration from the viewpoint of customers to assure its acceptability and, hence, its enforceability.

The theory of social preferences is helpful to derive some conditions which should be met by a fair and optimal tariff schedule. Social preferences not only take into account the utility derived from goods and services but also the distribution of consumption opportunities of other people. Individual well-being depends also on one's own endowment with goods in comparison to endowments of others. To capture the social nature of preferences, Fehr and Schmidt (1999) have introduced a social utility function to explain the somewhat paradoxical results from experiments, e.g.

\footnotetext{
${ }^{4}$ Mirrlees in his classical papers derives his results from a social welfare function with inequity aversion.
} 
the ultimatum game. We know from these experiments, that people are willing to forgo utility if they can prevent a proposed allocation they judge as unfair. This willingness cannot be explained by the traditional utility theory but requires to include preferences of fairness into individual's utility function. There are also other contributors to the theory of social preferences, e.g. Bolton and Ockenfels (2000) and Cox (2007). However, modeling inequity aversion requires to understand and to define what fairness means. The mere equity of material endowment or of well-being is only one special case. ${ }^{5}$ In general, various income distributions which are unequal might be perceieved as fair. This concept of "fair inequality" derives from liberal egalitarian theories of justice which consider an unequal income distribution as fair if it is the result of personal effort and talents. The institutional framework must offer equal opportunities and personal freedom to all people so as to guarantee the unrestricted conversion of talents and effort into income or well-being. ${ }^{6}$

In the following we want to utilize these concepts to derive a fair and, hence, acceptable water tariff system. To do so, we introduce a two stage approach.

- In the first stage a water provider or a regulation authority sets a tariff system. This stage is also called constitutional phase because the regulation authority acts on behalf of the customers. ${ }^{7}$;

- in the second stage customers make their consumption decision solely on the base of their own utility function. This does not contradict the social preference approach since the consumption decision is taken under the knowledge

\footnotetext{
${ }^{5}$ Fehr and Schmit, e.g., assume that an equal distribution of wealth is perceived as fair. Deviations from the principle of equal shares are perceived as unjust und lead to a diminishing level of well-being due to inequity aversion. Other contributions in the literature apply this framework to the equality of well-being (utility functions); see e.g. Rey-Biel, (2008).

${ }^{6}$ For the theory see Fleurbaey (2008) and Roemer (1998); empirical results are reported by Cappelen and Tungodden (2012) and Konow (1996). Fershtman, Gneezy and List (2012) showed within a modified dictator game that an unequal income distribution resulting from individual effort is socially accepted.

${ }^{7}$ Alternatively, we could think of a cooperative where customers jointly agree to a tariff system considered as fair.
} 
that tariffs have been set in accordance to fairness aspects in the first stage.

The main difference to the usual approach of maximizing total social welfare given the consumption behaviour of customers is that the regulator takes people's concern for fairness into account. To introduce the concept, we first confine the analysis to two customers. Later, we generalize the model to a continuous income distribution.

\subsection{A model with inequity aversion and distributional pref- erences}

Consider two identical customers 1 and 2 who only differ with respect to their income $y_{1}$ and $y_{2}$, respectively, where $y_{1}<y_{2}$. We assume that $y_{1}$ is sufficiently high to allow customer 1 to purchase the subsistence level of water for a price not less than marginal costs. Otherwise the construction of the tariff system reduces to the task to construct a tariff system such that the lower income class is able to have access to the subsistence level $w_{s}$ whereas the upper income classes faces a price well above average costs; in that case, the increasing block price structure is not the result of distributional considerations but ensues from the fulfillment of the principles of accessability and cost coverage.

The regulator introduces on behalf of cusmtomers a tariff system which consists of two outlay-quantity bundles

$$
\mathcal{T}_{i},=\left\{v_{i}, T_{i}\right\}, \quad i=1,2
$$

where $v_{i}$ is the water quantity offered for the amount of $T_{i}$. This quantity of water refers to water consumption above the subsistence level $w_{s}$. Total utility of consumers depends on water consumption including the subsistence level and the consumption of other goods that are represented by a basket $x_{i}$. In the following a Stone-Geary-utility function is employed:

$$
U(w, x)=\left(w-w_{s}\right)^{\alpha}\left(x-x_{s}\right)^{(1-\alpha)}
$$

where $w_{s}$ and $x_{s}$ are the subsistence level of water and of other goods, respectively. It is assumed without loss of generality that $x_{s}=0$. 
Since it is assumed, that the water supplier always secures at least the subsistence level $w_{s}$ we concentrate the analysis on water consumption in excess of the subsistence level

$$
v_{i}=w_{i}-w_{s}, \quad i=1,2
$$

This transformation allows to utilize a simple Cobb-Douglas utitlity function:

$$
U\left(v_{i}, x_{i}\right)=\left(v_{i}\right)^{\alpha}\left(x_{i}\right)^{(1-\alpha)}, \quad i=1,2
$$

Depending on what outlay-quantity bundle consumer $i$ chooses the following cases can be distinguished:

\begin{tabular}{lll}
\hline & $\mathcal{T}_{1}$ & $\mathcal{T}_{2}$ \\
\hline consumer1 & $U_{1}^{1}=\left(v_{1}\right)^{\alpha}\left(y_{1}-T_{1}\right)^{(1-\alpha)}$ & $U_{1}^{2}=\left(v_{2}\right)^{\alpha}\left(y_{1}-T_{2}\right)^{(1-\alpha)}$ \\
\hline consumer2 & $U_{2}^{1}=\left(v_{1}\right)^{\alpha}\left(y_{2}-T_{1}\right)^{(1-\alpha)}$ & $U_{2}^{2}=\left(v_{2}\right)^{\alpha}\left(y_{2}-T_{2}\right)^{(1-\alpha)}$ \\
\hline
\end{tabular}

It is assumed that both consumers chose the bundle $\mathcal{T}_{i}$ that leads to the highest utility level achievable.

Having determined the consumption decision of customers in stage 2 we now turn to stage 1 and discuss how customers with a concern of fairness assess the tariff system. To model the distributional concerns of customers we make use of the utility function introduced by Fehr and Schmidt (1999). In contrast to their specification, we assume that customers do not compare each other's absolute well-being but rather assess the given income distribution $\left\{y_{1}, y_{2}\right\}$ and its resulting differeneces in wellbeing. If the given income distribution and, hence, the utility distribution are held fair then the water tariff can be linear, charging each consumer according to her/his water use. We know from the literature that an unequal income distribution can be regarded as fair if it is based on responsibility factors, e.g. effort; in contrast, income inequalities are held unfair if they result from illegetimate power structures or other non-responsibility factors, as in Cappelen and Tungodden (2012). In the former case the water tariff is not to contribute to redistribution, in the later case the outlay-quantity bundles could be designed so as to reduce the unfair income distribution. 
If the given income distribution is regarded as fair the only requirements on the tariff system are economic viability and efficiency (marginal cost pricing). This is the case for the well known two-part tariff of Ronald Coase ${ }^{8}$ :

$$
T_{i}^{C}=t_{i}^{C}+c v_{i}, \quad t_{i}^{C}=\left(F+2 c w_{s}\right) / 2, \quad i=1,2
$$

where $F$ are fixed costs, $c$ are average variable costs and $2 c w_{s}$ are fixed costs due to the provision of the subsistence level of water. Assume that the cost function is given by

$$
C\left(v_{1}, v_{2}\right)=c\left(v_{1}+v_{2}\right)+F+2 c w_{s}, \quad c=\text { constant }
$$

From (7) it can be derived that the Coase tariff is economically viable.

To calculate the resulting utility distribution of customers for the given income distribution and the the two-part tariff applied insert (6) into the Cobb-Douglas function (4) and maximize it with respect to $v_{i}$. This yields

$$
v_{i}^{C}=\alpha\left(y_{i}-t_{i}^{C}\right) / c, \quad i=1,2
$$

By reinserting into (4) we get the indirect utility functions

$$
U_{i}^{C}=\Gamma\left(y_{i}-t_{i}^{C}\right), \quad \Gamma=(\alpha / c)^{\alpha}(1-\alpha)^{(1-\alpha)}, \quad i=1,2
$$

From (9) the utility difference

$$
\Phi^{C}=U_{2}^{C}-U_{1}^{C}=\Gamma\left(y_{2}-y_{1}\right)
$$

can be calculated which follows from introducing the two-part tariff of Coase. Obviously, utility is linear in income. If the given income distribution is regarded as fair, the utility difference $\Phi^{C}$ is also in accordance with the distributional beliefs of consumers.

However, if the given income distribution is regarded as unfair the distribution of utilities that results from the Coase tariff would also be unfair from the viewpoint of distributional beliefs. In this case, consumers would prefer a tariff system that

\footnotetext{
${ }^{8}$ See the explanation and discussion in Brown and Sibley (1986), p. 66-68.
} 
leads to a utility difference that falls short of $\Phi^{C}$ so as to make up for the unfair income distribution. The precise magnitude of

$$
\Phi<\Phi^{C}
$$

depends on the distributional beliefs and the efficacy of other redistributing instruments, e,g, taxes or other fiscal levers. If public authorities responsible for tax collection do function effectively then income would exhibit a fair distribution and, hence, $\Phi=\Phi^{C}$. If other redistributing instruments lack efficacy the water tariff system might also overtake the additional task of income redistribution, leading to the tariff requirement $\Phi<\Phi^{C}$. But usually, redistributing measures imply efficiency losses. Therefore, the question remains whether customers can live with a certain degree of unfair utility distribution in exchange for more total welfare. This depends on the degree of inequity aversion customers possess. The precise relationship can be captured by a utility function of the Fehr/Schmidt-type. These social utlity functions are introduced as preferences of customers within the first stage (constitutional stage).

$$
S U_{1}=U_{1}^{1}-\gamma_{1} \max \left[U_{2}^{2}-U_{1}^{1}-\Phi, 0\right]-\delta_{1} \max \left[\Phi-\left(U_{2}^{2}-U_{1}^{1}\right), 0\right]
$$

and

$$
S U_{2}=U_{2}^{2}-\gamma_{2} \max \left[\Phi-\left(U_{2}^{2}-U_{1}^{1}\right), 0\right]-\delta_{2} \max \left[U_{2}^{2}-U_{1}^{1}-\Phi, 0\right]
$$

The precise values of both utility levels depend, of course, on the tarif system $\mathcal{T}_{i}=$ $\left\{v_{i}, T_{i}\right\}, i=1,2$ implemented, customer's distributional beliefs $\Phi$ and the inequity aversion parameterized by $\gamma_{i}$ and $\delta_{i}$.

To derive the optimal tariff system we aggregate both social utility functions which yields

$$
S W F=U_{2}^{2}+U_{1}^{1}-\Delta_{1} \max \left[U_{2}^{2}-U_{1}^{1}-\Phi, 0\right]-\Delta_{2} \max \left[\Phi-\left(U_{2}^{2}-U_{1}^{1}\right), 0\right](14
$$

where $\Delta_{1}=\left(\gamma_{1}+\delta_{2}\right)$ and $\Delta_{2}=\left(\gamma_{2}+\delta_{1}\right)$. With respect to the weights of dissatisfaction we assume $\gamma_{i}>\delta_{i}$. In the experimental literature ${ }^{9}$ the distinction between

\footnotetext{
${ }^{9}$ Fehr, Klein and Schmidt (2007). The authors identify fairness with equality of income which is rooted in their social utility function that was developed for experimental environments. In terms of our model this is identical with the assumption $\Phi=0$.
} 
self-interested typs $\left(\gamma_{i}=\delta_{i}=0\right)$ and fair types is made. Fair types have a preference for fairness and are prepared to give up own income to achieve fairness. These typs exhibit values. ${ }^{10} . \gamma_{i} \geq \delta_{i}>0.5$. In the following we restrict our analysis to customers of the fair typ. As a result it follows that $\Delta_{1}>1$ and $\Delta_{2}>1$ which implies that the aggregated effect of inequity aversions of both customers exceeds the direct utility effect of increased well-being at the expense of more inequity. ${ }^{11}$ In this sense, both customers within the constitutional stage exhibit strong social preferences weighting distributional issues stronger than their own well-being.

The derivation of the optimal tariff system is achieved by maximizing (14) subject to the budget constraint

$$
T_{1}+T_{2}-c\left(v_{1}+v_{2}\right)-F-2 c w_{s} \geq 0
$$

and the incentive compatibility constraints

$$
U_{1}^{1} \geq U_{1}^{2} \quad \text { and } \quad U_{2}^{2} \geq U_{2}^{1}
$$

These constraints are required since customers are free to choose the outlay quantity bundles offered. Tariffs cannot directly be linked to income, either because income is not observable, or because the water price must solely be linked to the underlying good water.

Due to the kink of SWF at $U_{2}^{2}-U_{1}^{1}=\Phi$ the optimization procedure has to be split in two subcases ${ }^{12}$. First SWP will be maximized subject to the constraints (15), (16) and the additional constraint

$$
U_{2}^{2}-U_{1}^{1} \geq \Phi
$$

In the second subcase SWP will be maximized again subject to (15) (16) and

$$
U_{2}^{2}-U_{1}^{1} \leq \Phi
$$

\footnotetext{
${ }^{10}$ If, in addition, $\gamma_{i} \leq 1$ and $\delta_{i} \leq 0.5$ inequity aversion is called non-dominant, see Rey-Biel (2008).

${ }^{11}$ The linearity of inequality aversion implies a constant elasticity of substiution between own wellbeing and inequality which might be questioned. In the literature other social utility function are discussed. To keep the model simple we have restricted ourselves to the case of linearity. For further developments see Cox, Friedman and Gjerstad (2007).

${ }^{12}$ All details are deferred to the appendix.
} 
The optimal tariff system exhibits the following properties

\section{lemma 1}

1. In the presence of inequity aversion and redistributional preferences, i.e. $\Phi<$ $\Phi^{C}$, the optimal outlay-quantity bundels $\mathcal{T}_{i},=\left\{v_{i}, T_{i}\right\}, \quad i=1,2$ exhibit the following properties:

(a) if $\Phi^{I C} \leq \Phi<\phi^{C}$ then

$$
\mathcal{T}_{1}=\left\{v_{1}\left(c, t_{1}\right), t_{1}+c v_{1}\left(c, t_{1}\right)\right\} \quad \mathcal{T}_{2}=\left\{v_{2}\left(c, t_{2}\right), t_{2}+c v_{2}\left(c, t_{2}\right)\right\}(19
$$

where $v_{1}\left(c, t_{1}\right)=\alpha\left(y_{i}-t_{i}\right) / c, i=1,2$ and $t_{1}+t_{2}=F+2 c w_{s} . \Phi^{I C}$ is the utility difference regarded as fair that can be achieved such that the incentive compatibility constraints (16) are just not binding. The optimal utility difference equals the difference $\Phi$.

(b) if $\Phi^{s b} \leq \Phi<\Phi^{I C}$ then $\mathcal{T}_{i}, i=1,2$ are such that the optimal utility difference equals the difference $\Phi$, i.e. utility grows with income exactly according to the redistributional preferences. $\Phi^{\text {sb }}$ is the fair utility difference that results from maximizing the SWP under the respective constraints assuming that the constraint (17) is not binding.

(c) if $\Phi<\Phi^{s b}$ the then $\mathcal{T}_{i}, i=1,2$ are such that $U_{2}^{2}-U_{1}^{1}>\Phi i$. e. the optimal utility difference exceeds the difference $\Phi$, i.e there exist an optimal deviation from the fair utility distribution parameterized by $\Phi$.

2. In the presence of inequity aversion and distributional neutrality, i.e. $\Phi=\Phi^{C}$, the optimal tariff system is a Coase-tariff. Utility grows in a linear manner with respect to income.

3. $U_{2}^{2}-U_{1}^{1}<\Phi$ is never optimal, i.e. the optimal tariff system is never redistributional to such an extent that the utility difference is less than the fair difference.

Proof see appendix 6.1. 
The main result of proposition 1 is that for a broad range of redistributional preferences the optimal tariff system ties the optimal utility difference to the fair utility difference. If the income distribution is regarded as unfair then the optimal tariff system should be constructed such that the resulting utility difference follows the fair utility difference that falls short of that differential of wellbeing of both income groups in the case of the linear Coase tariff. Even efficiency losses are accepted to secure this distributional goal. This strong result derives from the distinctive inequity aversion $\left(\Delta_{i}>1\right)$. The result also depends on the strength of distributional preferences. The following figure illustrates the interrelations.

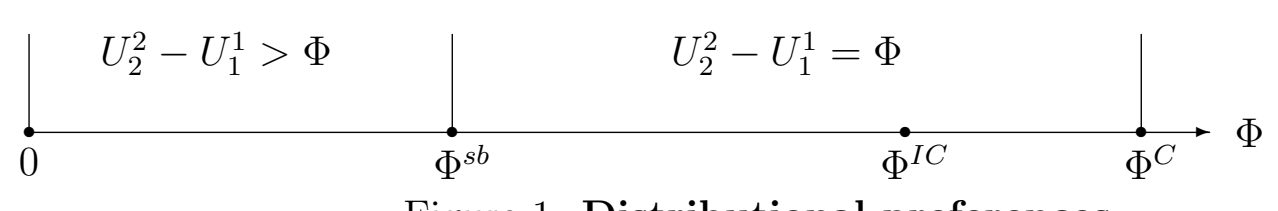

Figure 1: Distributional preferences

Let us assume, that $\Phi$ lies between $\Phi^{I C}$ and $\Phi^{C}$ then the distributional goal can be achieved even without activating the incentive compatibility constraints (16). Hence, the distributional goal can be achieved without efficency losses. If distributional preferences $\Phi$ are such that, $\Phi^{s b} \leq \Phi<\Phi^{I C}$, then the optimal utility difference resulting from the adoption of the optimal tariff system is equal to the fair difference $\Phi$. In contrast to the former interval this can only be achieved at the expense of efficiency losses. If distributional preferences are very strong, such that $\Phi<\Phi^{s b}$ then it is optimal to live with some unfair utility difference, i.e. $U_{2}^{2}-U_{1}^{1}>\Phi$. Meeting the distributional goal is to expensive in terms of efficiency losses.

The following figure ${ }^{13}$ displays the Coase scenario and case 1. (a) of the proposition.

\footnotetext{
${ }^{13}$ The following two figures are drawn for the following paramtere values: $\alpha=1 / 3, y_{1}=1000$, $y_{2}=1800, \Delta_{1}=1.3, w_{s}=20, F=140, c=1.5$.
} 


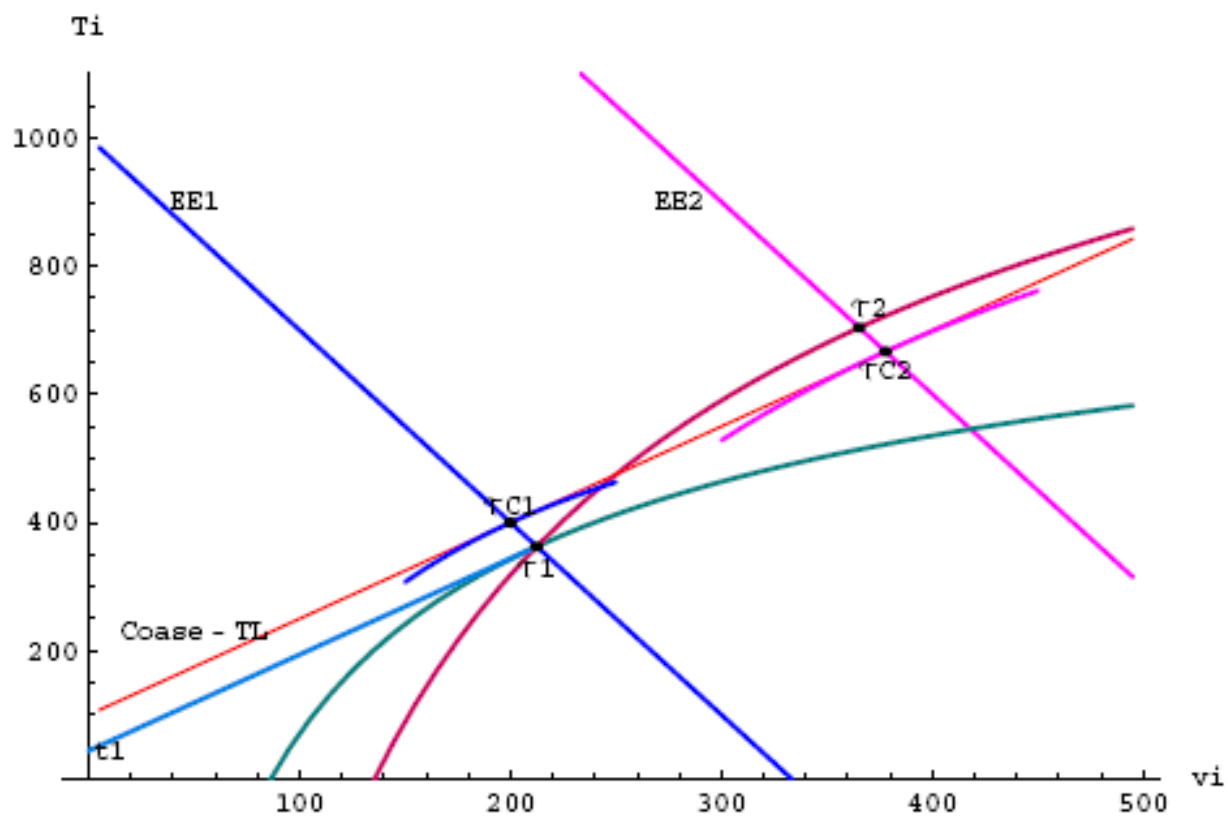

Figure 2: Coase tariff and fair tariffs for case 1.(a)

If $\Phi^{C}$ is regarded as fair (distributional neutrality), the optimal outlay-quantity bundles are located at $\mathcal{T}_{1}^{C}$ and $\mathcal{T}_{2}^{C}$, respectively. The efficiency of the Coase tariff follows from the property that both tariffs are calculated by equating the Coasetariff $^{14}$ line $T L=\left(F+2 c w_{s}\right) / 2+c v$ with the efficiency lines $E E_{i}$. These lines show all $T_{i}-v_{i}$-combinations for which the marginal rate of substitution is equal to marginal costs, i.e.

$$
U_{i v} / U_{i y}=c \Rightarrow y_{i}-T_{i}=\frac{(1-\alpha) c v_{i}}{\alpha}, \quad i=1,2 .
$$

The respective indifference curves at $\mathcal{T}_{1}$ and $\mathcal{T}_{1}$ indicate the utility levels of both income groups. If, however, $\Phi<\Phi^{I C}$ the indifference curve of consumer 1 (2) must be more towards the south east (north west) such that the incventive compatibility constraint $U_{2}^{2}=U_{2}^{1}$ is exactly fulfilled. ${ }^{15}$

It is interesting to observe, that for this case the optimal tariff system is also efficient, i.e. the outlay-quantity bundels lie along the efficiency lines at $\mathcal{T}_{1}$ and $\mathcal{T}_{2}$,

\footnotetext{
${ }^{14}$ See (6).

${ }^{15}$ Note, that the first IC-condition $U_{1}^{1}>U_{1}^{2}$ is not binding due to the single crossing condition.
} See appendix 6.1 . 
respectively. At the same time they are incentive compatible. Efficiency and incentive compatibility apply because the tariff system fixes quantities, i.e. includes quantity rationing. Consumer 2 can switch from tarif $\mathcal{T}_{2}$ to tarif $\mathcal{T}_{1}$ which is cheaper in terms of the cost coverage of total fixed costs (see the $t_{1}$-line in comparison to the Coase-TL-line in figure 2). But she cannot gain more utility because consumption is constraint to $v_{1}$.

If $\Phi^{C}$ lies in the intervall $\left[\Phi^{s b}, \Phi^{I C}\right)$ distributional preferences are strong to an extent that requires to accept efficiency losses. The following figure depicts this case ${ }^{16}$.

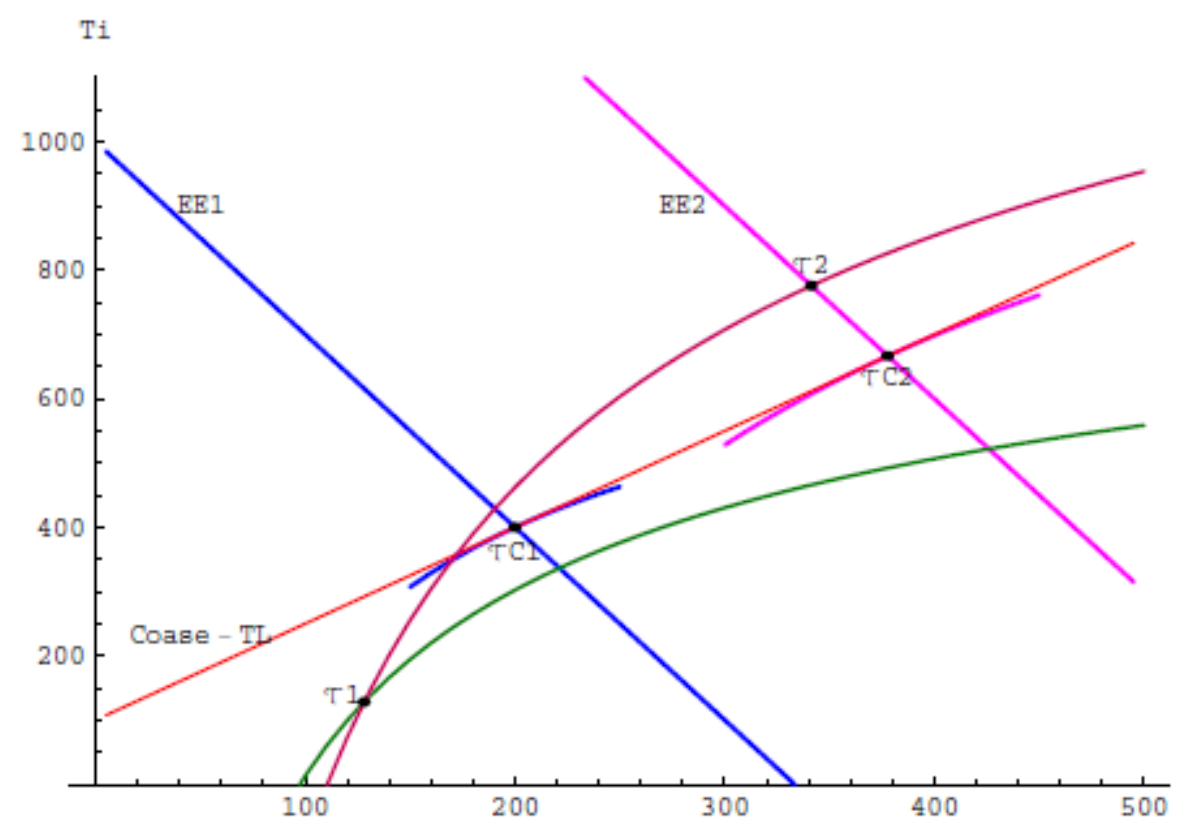

Figure 3: Fair tariffs for case 1.(b)

The optimal outlay-quantity bundels $\mathcal{T}_{i}, i=1,2$, are designed such that the utility of income group 1 (2) does increase (decrease) in comparison to the utility levels in the Coase tariff case. Moreover, efficency losses for income group 1 is observable whereas efficiency for income group 2 maintains which is a standard property of optimal price discrimination. ${ }^{17}$ Notice that for this intervall the optimal tariff system seccures a

\footnotetext{
${ }^{16}$ The figure is drawn under the assumption that $\Phi=250$.

${ }^{17}$ See e.g. Goldman, Leland, and Sibley (1984)
} 
utility difference that equals exactly the difference of wellbeing which is regarded as fair. Only in the case of extreme distributional preferences (case 1.(c) of the lemma) efficiency losses have grown to such an extent that it is optimal to deviate from the fair utility difference. These efficiency losses are the consequences of the need to seperate both income groups by a system of incentive compatible outlay-quantity bundles. Assume for explanatory purposes that the distributional preferences are completly egalitarian, i.e. $\Phi=0$. From the incentive compatibility constraints (16) and from the single crossing property ${ }^{18}$ we can infer $U_{2}^{2}>U_{1}^{1}$. Hence, the optimal utility difference is higher than the wellbeing differential $\Phi$ regarded as fair. In the following we exclude this case from the analysis assuming that the water tariff system is not mainly in charge of redistributional tasks. There are other redistributional instruments that stay in the center of distribution and social policy. This, of course, does not exclude that the water sector does contribute to distributional goals to a certain extent.

\section{The continuous model}

In the following, the two-income-group model will be extended to the case of a continuous income distribution under the assumption that ineuqity aversion and distributional preferences are such that optimality leads to a tariff system that completely ties the optimal utility difference to the fair difference of utility (cases ${ }^{19} 1$. (a) and (b) of lemma 1). After presenting the basic model, we turn to the fairness concept in the case of a continuous income distribution and the resulting progressive tariff. Finally, a simple numerical example shows how material wellbeing and fairness relate to each other.

\footnotetext{
${ }^{18}$ The single crossing property leads to $U_{2}^{i}>U_{1}^{i}, i=1,2$. See the appendix 6.1.

${ }^{19}$ Notice, that in the continuous case the intervall $\left[\Phi^{I C}, \Phi^{C}\right]$ contracts to zero as $y_{1}$ approaches $y_{2}$. Of course, the intervall $\left[\Phi^{s b}, \Phi^{C}\right]$ remains.
} 


\subsection{Incentive compatibility}

Just like in the previous section, consumers choose between water and some other goods which are aggregated into a basket. Consumers differ with respect to income: we assume a continuum of incomes beginning with very poor households followed by a middle class and ended by rich customers. Income is distributed according to a density function $g(y)>0, \forall y \in Y=[\underline{y}, \bar{y}]$. The total number of people of income $y$ is $P g(y)$, where $P$ is total number of customers. In the basic model we assume that households differ only with respect to income. Later we will include the household size into the analysis.

Similar to the discrete case laid out above, poor people are entitled to receive a certain amount of water for an affordable price; this is captured by the specific Stone-Geary-utility function (2). In addition, the water tariff system is constructed such that water expenses depend on water consumption and income. This can be denoted by a tariff plan (TP)

$$
T P:=\{T(y), w(y)\}, \quad \forall y \in Y=[\underline{y}, \bar{y}]
$$

where $y$ denotes income in the interval $Y$ and $T(y)$ is a continuous outlay function of customers to be determined subsequently. $w(y)$ is the respective profile for water consumption. Note that the usual tariff system $T(w)$ can be derived from (21).

The affordability of water supply requires that poorest can buy their subsistence level of water. Hence TP is constructed such that

$$
T(\underline{y})=\underline{y} \quad \text { and } \quad w(\underline{y})=w_{s}
$$

(22) secures that all customers have access to water, even if the poor cannot afford water priced by marginal costs, i.e. $y<c w_{s}$.

Taking the tariff plan TP into account, the budget constraint of households can be derived:

$$
T(y)+p_{x} x \leq y
$$

where $p_{x}$ is the price of the other good. For simplicity we calibrate the measure of $x$ such that $p_{x}=1$. 
Similar to the two-income-group mode we define

$$
v=w-w_{s} \quad \text { and } \quad z=y-\underline{y}
$$

where $v$ is the water consumption in excess of the subsistence level and $z$ is income above the minimum $\underline{y}$ and is distributed according to the density function $f(z)=$ $g(z+\underline{y})>0, \forall z \in Z=[0, \bar{y}-\underline{y}]$.

Using (24), the budget constraint can be transformed to

$$
T(z)+p_{x} x \leq z
$$

If we insert (25) into (2) we obtain

$$
U(v(z), z-T(z))=(v(z))^{\alpha}(z-T(z))^{(1-\alpha)}
$$

Just like above, as water utilities cannot observe income (or are not allowed to ask for income details), the tariff system has to be built up in a way that customers have an incentive to tell their true income. This requires that the tariff plan be constructed in an incentive-compatible way. From the revelation principle we know that an incentive compatibility for the continuous case satisfies the following incentive constraint: ${ }^{20}$

$$
z=\operatorname{argmax}_{\tilde{z}}[U(v(\tilde{z}), z-T(\tilde{z}))]
$$

(27) requires that $v(z)$ and $T(z)$ be chosen such that customers do report their true income to the water company. The respective properties can further be inspected if we differentiate (27) with respect to $\tilde{z}$ and set $\tilde{z}=z$.

$$
U_{w} \dot{v}(z)-U_{y} \dot{T}(z)=0, \quad \forall z \in Z
$$

where dots denote the derivatives with respect to $z$.

Utilizing the Cobb-Douglas utility function yields:

$$
\frac{\alpha \dot{v}(z)}{v(z)}-\frac{(1-\alpha) \dot{T}(z)}{z-T(z)}=0, \quad \forall z \in Z
$$

\footnotetext{
${ }^{20}$ See e. g. Mas-Colell et al. (1995, p. 492 ff.) or Wolfstetter (1999, p. 259 ff.).
} 
(29) implicitly determines some characteristics of the admissable tariff systems. From the second order conditions ${ }^{21}$ it also follows that

$$
\dot{v}(z)>0 \quad \text { and } \quad \dot{T}(z)>0 \quad \forall z \in Z
$$

We continue to assume the following simple cost function:

$$
C(V(z))=F+c V(z)+P c w_{s},
$$

where $F$ are fixed costs, $c$ is a positive constant and

$$
V(z)=P \int_{0}^{z} v(z) f(z) d z
$$

is the aggregated water consumption for all incomes up to $z$.

\subsection{Fairness in the continuous case}

Lemma 1 showed that for a broad range of distributional preferences the optimal tariff system sets outlay-quantity bundles such that the wellbeing of income classes develop according to $\Phi$. The redistributional effects of these optimal bundles can be identified by observing that the resulting allocations $\mathcal{T}_{i}$ improves the wellbeing of the lower income class in expense of a deterioration of wellbeing of the upper class. In the continuous case the utility differenence $\Phi$ has to be extended to a function $\Phi(z)$ for all $z$ in $[0, \bar{y}-\underline{z}]$ so as to determine the fair utility levels of income classes for the whole income range.

If distributional neutrality prevails the utility of customers is a linear function of income (recall (9)). Utilizing this utility function we define

$$
\phi^{C}(z)=\frac{d U^{C} / U^{C}}{d z / z}=1
$$

In the continuous case the utility difference is transformed to an utility differential. Due to the linearity of the Coase-utility function the income elasticity is equal to one.

\footnotetext{
${ }^{21}$ These condition must hold to guarantee a separating equilibrium, i.e. that $v(z)$ and $T(z)$ vary with respect to $z$, see appendix 6.2 .
} 
However, if customers exhibit distributional preferences the fair growth of utility with respect to income cannot be linear. Instead one obtains the following differential equation:

$$
\phi(z)=\frac{d U(v(z), z-T(z)) / U(v(z), z-T(z))}{d z / z}=1-\epsilon<1
$$

(34) is a requirement that a fair tariff system must conform to.

We assume that $\Phi(z)=(1-\epsilon)$ is constant. This assumption implies that distributional preferences do not change as income rises. The parameter $\epsilon$ indicates the strenght of distributional preferences.

Inserting the incentive compatible tariff plan TP into the utility function (26) and utilizing the IC-condition (28) (34) can be expressed as:

$$
\phi(z)=\frac{(1-\alpha) z}{z-T(z)}=(1-\epsilon)
$$

This fairness condition prescribes how income and expenses are related if distribution matters.

\subsection{Progressive Tariffs}

Having introduced the incentive compatibility constraint and the fairness condition the next task is to derive the tarif system. From (35) it follows

$$
T(z)=\frac{z(\alpha-\epsilon)}{(1-\epsilon)}
$$

Differentiating $T(z)$ and inserting into (29) yields

$$
\alpha \frac{\dot{v}(z)}{v(z)}=\frac{\alpha-\epsilon}{z}
$$

This non-linear differential equation can be solved leading to

$$
v(z)=S z^{((\alpha-\epsilon) / \alpha)}
$$

where $\mathrm{S}$ is a constant which will be determined later. Notice that the solution is only valid if $a>\epsilon$. Otherwise, water consumption would decrease with income $z$ which violates the incentive compatibility constraint (second order condition). 
To finde the tariff function one has to solve (38) for $z$ and to insert the result into (36). This yields the tariff function

$$
T(v)=\left(\frac{a-\epsilon}{(1-\epsilon) S}\right) v^{(a /(a-\epsilon))}
$$

proposition 1 If inequity aversion and distributional preferences $(\alpha>\epsilon>0)$ are such that the optimal utility function $\mathcal{V}(z)=U(v(z), z-T(z))$, where $\{v(z), T(z)\}$ are defined in (36) and (38) respectively, follows the fair growth of wellbeing defined in (34) then the resulting optimal tariff function (39) is progressive. In the case of distributional neutrality $(\epsilon=0)$ the tariff function is linear.

The proof follows from the outlay-quantity functions (38) and (36).

The tariff function (39) exhibits a clear relationship between progressivity and the distributional preferences. If $\epsilon>0$, then customers exhibit distributional preferences; as a result, the tariff function is progressive. If $\epsilon=0$ the tariff function is linear. This is in contrast to the literature on optimal tariffs ${ }^{22}$ where the marginal price can decrease as income rises for certain income intervalls. If $\epsilon=0$ the tariff system guarantees the access to water by constuction but it is not redistributive. Instead, it is a simple two-part tariff of the form $T(w)=\underline{y}+T(v), w \geq w_{s}$, similar to what has been proposed by Boland and Whittington (2000, p. 9 sq.) and Whittington (2003, p. 70).

The optimality of the tariff function (39) follows from lemma 1. If the social welfare function is the aggregation of individual social utility function of customers in the constitutional stage exhibiting unequity aversion such that $\Delta_{i}>1$ and if distributional preferences are not to strong then the optimal growth of wellbeing with respect to income follows exactly the utility growth perceived as fair. This requires a progressive tariff function.

\footnotetext{
${ }^{22}$ See Diakite, Semenov and Thomas (2009) or Goldman, Leland and Sibley (1984).
} 


\subsection{Numerical Example}

\subsubsection{Parameter definition}

The tariff system $\{v(z), T(z)\}$ captures both, water consumption, affordability and fairness. It remains to assure that the water provision under this tariff system is economically viable, i.e. covers the production costs. Utilizing (31) and (32) cost coverage requires that

$$
\int_{0}^{\bar{y}-\underline{y}} T(z) f(z) d z-c V(\bar{y}-\underline{y})+\underline{y}-c w_{s}-F / P=0
$$

This condition allows to calculate $S$ from (38) for various values of $\epsilon$. In general, it is not possible to find an analytical soultion. Therefore, we utilize a simple numerical example to show how cost coverage and distributional preferences are linked together. The following paramteres have been specified:

\begin{tabular}{|c|c|c|c|c|c|c|}
\hline $\mathrm{c}$ & $\underline{y}$ & $\bar{y}$ & $w_{s}$ & $\alpha$ & $\mathrm{F}+P c w_{s}$ & $\mathrm{P}$ \\
\hline 1 & 10 & 100,000 & 20 & 0.5 & $20,000,000$ & $23,000,000$ \\
\hline
\end{tabular}

In addition, we assume that income is distributed according to a exponential density function with density function $k e^{-k z}, k=0.01$. This captures an unequal income distribution were the probability mass is concentrated on the lower income. ${ }^{23}$

\subsubsection{Economic viability}

The following figure shows how $S$ depends on $\epsilon$ to guarantee the coverage of costs (40).

\footnotetext{
${ }^{23}$ The exponential distribution is not only applied to study the income distribution in developing countrties but also for developed countries. See e.g. Dragulescu and Yakovenko (2000). In our example the median income is roughly 70 .
} 


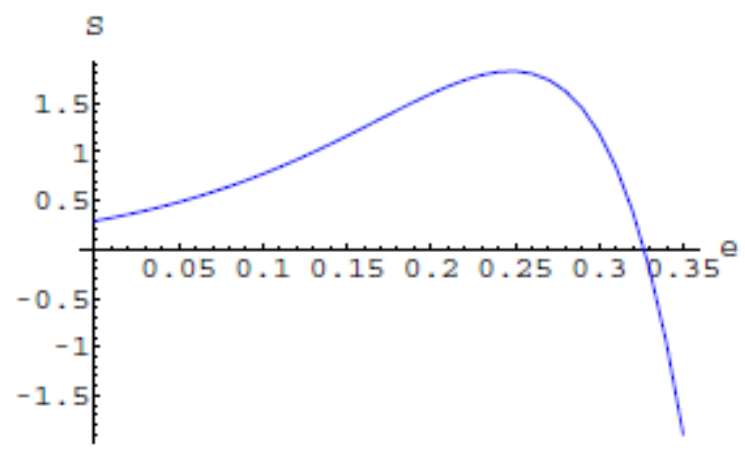

Figure 4: Economic viability

The graph shows that at first $S$ increases due to the tightening of the progression forcing the upper income classes to more profit margin. As a result, water demand of low and medium income rises (see (38)). But this leads to higher costs and, at the same time, requires more revenue. As progressivity rises water demand of the high income reduces which leads to less revenue. Hence, after $S$ has reached the maximum it decreases. Cost coverage comes now increasingly from middle and low incomes. At approximately $\epsilon=0.32$ economic viability ceases, because the strong progessivity of the water tariff has lead to lower cross subsidies of the high incomes. At the same time, middle and low income cannot cover all costs including the subsistence level for all incomes.

\subsubsection{Threshold income}

Tightening the progression does not only lead to a greater contribution to profit margin of the upper classes; it also shifts the income threshold between lower incomes cross-subsidized and income ranges cross-subsidizing. Define the threshold as

$$
z^{c c}: T(z)-c v(z)=0
$$

Utilizing (36) and (38) we can calculate the threshold for all admissible $\epsilon$. This yields the following figure: 


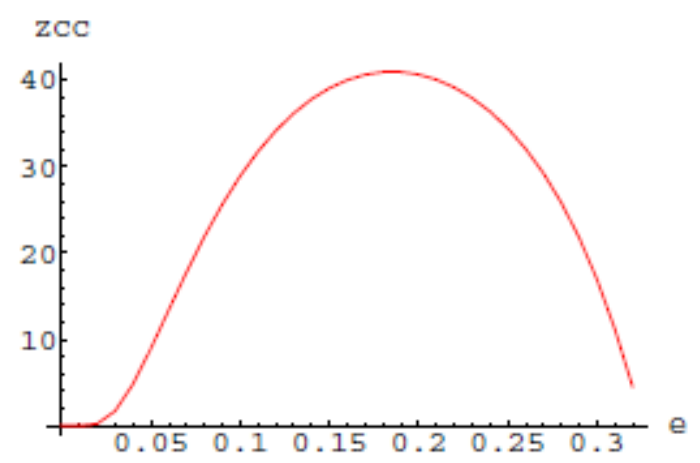

Figure 5: Threshold income

The figure shows that for lower values of $\epsilon$ the income threshold $v^{c c}$ increases leading to a more expanded income band which is cross-subsidized. Starting from $\epsilon=0$ more progression allows to get more profit margin from the higher income range and, at the same time, more cross-subsidization for the lower incomes. This increases water demand and decreases water expenses of the lower income groups. In the course of increasing $\epsilon$ more customers are subsidized by the upper incomes. But, due to the exponential distribution there are not many upper incomes remaining and, as a result, a financing gap will occur which has to be covered by an increased contribution of the middle incomes. Thus, in the course of further tightening the threshold reaches a maximum and then decreases. At a certain threshold, $S$ will decrease such that the threshold income $v^{c c}$ will decrease. The figure shows that certain levels of $v^{c c}$ can be achieved by, both, low and a high distributional preferences. Obviously, a strong progression lowers the income range receiving cross-subsidization.

\subsubsection{Material wellbeing}

The extent of material well being of the low income range depends of course on $\epsilon$. Let us define low income as the sum of $\underline{y}$ and half of average income $z$, i.e. $y^{\text {poor }}=\underline{y}+0.5 E[z]$. Inserting (36) and (38) into (26) yields

$$
\mathcal{V}(z)=S^{\alpha}\left(\frac{1-\alpha}{1-\epsilon}\right)^{1-\alpha} z^{1-\epsilon}
$$

Total welfare of households with $z \in[0,0.5 E[y]-\underline{y}]$ can be derived by integrating (42) with respect to $z$ over the relevant income interval. To compare material wellbeing 
of the lower incomes with total wellbeing we also calculate the total integral of the range $[0, \bar{y}-\underline{y}]$. The following figure shows both graphs as a function of $\epsilon{ }^{24}$

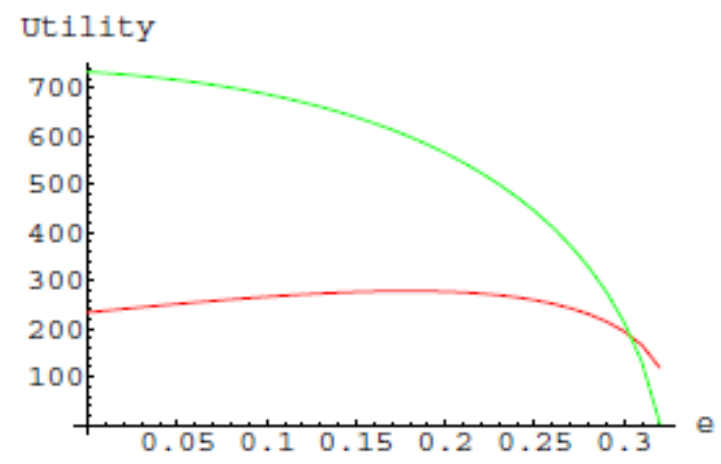

\section{Figure 6: Low versus total income wellbeing}

The figure shows that material wellbeing of low income groups is not a positive monotonic function of distributional preferences. There exists a value of $\epsilon$ which leads to the maximal material wellbeing of the low income range due to the economic viability constraint of water supply explained above; as $\epsilon$ increases further, the material wellbeing of the poor decreases. This is due to the fact that the threshold of redistribution moves to lower incomes, and that the "almost poor" start to support the very poor.

Note that $\epsilon$ can not be chosen by a regulator; rather $\epsilon$ is exogenous, as it represents the distributional preferences of a community of water customers. Lower aggregated material wellbeing does not imply lower welfare if we recall the strong satisfaction customers derive from the fulfillment of distributional preferences.

\footnotetext{
${ }^{24}$ The total welfare function is rescaled by a additive constant so as to depict both function in a compact diagram. It is the shape of the curves that are of analytical interest not their absolut values.
} 


\section{Including the household size into the tariff sys- tem}

A major shortcoming of IBTs in practice is that they do not take into account the size of households. Some tariff systems should construct the first block taking into account a best guess of household size of the poor. In the following we explicitly introduce the number of household members into the tariff. ${ }^{25}$ Two methods are conceivable:

- The tariff is based on reported income and the reported number of household members. This requires a tariff schedule of the form $T(y, h), W(y, h)$, where $y$ is total household income and $h$ the household size. $T$ and $W$ are defined for households and not for individuals. This scheme is very difficult to design if there is no additional information available. It requires to solve partial differential equations. The resulting tariff schemes are sensitive with respect to the relevant parameters. Of course, if reliable information on income and household size is available, first best tariffs can be implemented. ${ }^{26}$

- The tariff is based solely on reported income. This approach does not require households to report their size. The number of household members is estimated utilizing econometric methods. The resulting size function depends on income and is included in the tariff scheme. The advantage is of this approach lies in its simplicity, whereas on the other hand it lacks precision. The statistical

\footnotetext{
${ }^{25}$ Agthe and Billings (1987) analyze the relation between household income levels and residential water use for Tucson, Arizona. The demand models show that "under the existing increasing block rate pricing schedules, higher income households not only use more water, but have lower elasticities of demand" (p. 273). This implies that a uniform proportional increase will cause a larger percentage drop in water use among low income households than among high income households. Agthe and Billings (1987, p. 273) therefore argue in favor of substantially steeper block rates to improve interpersonal equity in water pricing.

${ }^{26}$ In Chile, for example, some districts have implemented a so called "means-tested" approach where households have to verify their income and their size. If they fall short of certain social standards they receive water for a highly subsidized price, see Gómez-Lobo and Contreras (2003).
} 
relationship between household size and income is valid on average. Some households may have more members than others. This might lead to an unfair treatment of some households.

In the following we take the second approach and include the household size function into the tariff system assuming a deterministic relationship between income and household size. The size function is assumed as follows: ${ }^{27}$

$$
h(z)=A z^{-r}, \quad r \geq 0
$$

The assumed negative correlation between income and household size is based on the strong empirical evidence that the number of household members and household income are negatively correlated, e.g. Jones, et al. (2008).

Assuming, that the household maximizes the aggregate welfare the incentive compatibility constraint can be derived by applying (27), i.e.

$$
z=\operatorname{argmax}_{\tilde{z}}[h(z) U(V(\tilde{z} / h(z),(z-T(\tilde{z})) / h(z))]
$$

where $V(z)$ is total water consumption in addition to $h(z) w_{s}$, and $T(z)$ is total expenses for water. Households maximize aggregate utility by chosing the optimal message $\tilde{z}$. If the tariff system $T(z), V(z)$ is incentive compatible $\tilde{z}=z$. The first order condition requires:

$$
U_{w} \dot{V}(z)-U_{y} \dot{T}(z)=0, \quad \forall z \in Z=[0, \bar{y}-\underline{y}]
$$

The second order condition requires $\dot{V}(z)>0$ and $\dot{V}(z)>0$.

Utilizing the Cobb-Douglas utility function (45) can be expressed as:

$$
\frac{\alpha \dot{V}(z)}{V(z)}-\frac{(1-\alpha) \dot{T}(z)}{z-T(z)}=0, \quad \forall z \in Z
$$

\footnotetext{
${ }^{27}$ This function is chosen to keep the modell analytically tractable. Strictly speaking, this function can only be a approximation of the relationship since for $z=0$ the household size would tend to infinity. But if we start for a very low level of $z=\underline{z}>0$, the parameters $A$ and $r$ can be chosen so as to depict emprically reasonable values. If we supplement the numerical example for $\underline{z}=0.1$, $h(\underline{z})=7$ and $h(\bar{z})=1$, then $A=4.74$ and $r=0.17$.
} 
The fairness of the tariff system follows from the fairness condition ${ }^{28}(34)$

$$
\mathcal{V}(z)_{z} z / \mathcal{V}(z)=\Phi(z)=\frac{(1-\alpha) z}{z-T(z)}+r=(1-\epsilon)
$$

From (47) one can derive the expense function

$$
T(z)=\frac{(\alpha-\epsilon-r) z}{1-\epsilon-r}
$$

which differs from (36) only with respect to the distribution parameter $r$ of the household size function. Differentiating (48) with respect to $z$ an inserting into (46) leads to the following differential equation:

$$
\left.\frac{\alpha \dot{V}(z)}{V(z)}=\frac{(\alpha-\epsilon-r}{z}\right)
$$

which can be solved yielding

$$
V(z)=S z^{\left.\frac{(\alpha-\epsilon-r}{\alpha}\right)}
$$

where $S$ is a constant chosen such that economic viability is achieved (cf. (40). ${ }^{29}$ Finally, the tariff function for the case of multimember households can be derived by solving (50) for $z$ and inserting into (48). After some calculations this yields

$$
T(V)=\frac{\alpha-\epsilon-r}{1-\epsilon-r}\left(\frac{V^{\frac{\alpha}{\alpha-\epsilon-r}}}{S}\right)
$$

The curvature depends not only on distributional preferences but also on the household size function. If the negative correlation between household size and income is strong then the progressivity of the tariff function is also strong. Even if distributional preferences are neutral $(\epsilon=0)$ the tariff function remain convex, i.e. it exhibits progressivity, if $r>0$. The level of the tariff function is determined by $S$ which secures cost coverage.

\footnotetext{
${ }^{28}$ The derivation is carried out in appendix 6.3

${ }^{29}$ Notice that the solution is only valid if $\alpha-\epsilon-r>0$. Hence, for strong distributional preferences and a strong relationship between income and household size there does not exist a tariff function which can be solely be built on water consumption. In this case, the water supplier has to rely on a comprehensive social welfare office that collects the necessary data, to identify income and size of households of the water customers.
} 


\section{Conclusions}

Many developing countries around the world apply progressive water tariffs, often structured in the form of discretely increasing block tariffs (IBTs), but there is a controversial debate about the pros and cons of this approach. This paper addresses the empirical fact that many developing countries around the world apply progressive water tariffs, often structured in the form of discretely increasing block tariffs (IBTs). While traditionally, this has been justified by the need to assure a balanced budget for the water utility in a poverty context, where a subsistence level of water has to be allocated to each household below average costs, we explore an alternative explanation for the tariff structure, which is motivated by fairness considerations: developing upon a utility function including inequality aversion, we add a parameter for the "preference for redistribution", and calculate "optimal" fair prices set by a regulator. Thus, we find an alternative interpretation of increasing block tariffs than previously held. The paper also includes household size in the analysis, finding that as poor households are on average larger (in per capita terms), a simple IBT tariff disregarding household size may not be "fair" at all. More empirical work on StoneGeary demand for water is necessary to underpin the theoretical findings, both for water-poor areas in developed countries, and in emerging and developing countries.

\section{Appendix}

\subsection{Proof of proposition 1}

Models of optimal price discrimination usually rely on the single crossing property condition of the incentive compatibility constraints. This condition is implicitly fulfilled by the Cobb-Douglas utiliy function used in our model. Formally:

$$
S=\frac{\partial\left(U_{v}(.) / U_{z}(.)\right)}{\partial z}>0
$$

From (4) it follows

$$
U_{v}(.) / U_{z}(.)=\frac{\alpha(z-T(z))}{v(z)(1-\alpha)}
$$


and hence

$$
S=\frac{\alpha}{v(z)(1-\alpha)}>0
$$

It is well known, that in this case both incentive compatibility constraints can never be binding at the same time for $v_{1} \neq v_{2}$ and $T_{1} \neq T_{2}$ (see figure (3)). Also we have

$$
v_{1}<v_{2} \quad \text { and } \quad T_{1}<T_{2}
$$

which follows from inserting (4) into the incentive compatibility constraints (16).

To prove the proposition the first order conditions of the two maximization programs have to be derived. We begin with the first program :

$$
\max _{\left\{v_{i}, T_{i}\right\}}\left[U_{2}^{2}+U_{1}^{1}-\Delta_{1} \max \left[U_{2}^{2}-U_{1}^{1}-\Phi, 0\right]\right]
$$

subject to the profit constraint (15), constraint (17) and the incentive compatibility constraints

$$
\mathrm{IC} 1 \geq 0: \quad U_{1}^{1}-U_{1}^{2} \geq 0
$$

and

$$
\mathrm{IC} 2 \geq 0: \quad U_{2}^{2}-U_{2}^{1} \geq 0
$$

where the $U_{i}^{j}$ are defined in (5).

Assuming an interior solution we have:

$$
\begin{aligned}
U_{1 v}^{1}\left(1+\Delta_{1}-\mu\right)-\lambda c+\sigma U_{1 v}^{1}-\xi U_{2 v}^{1} & =0 \\
U_{2 v}^{2}\left(1-\Delta_{1}+\mu\right)-\lambda c-\sigma U_{1 v}^{2}+\xi U_{2 v}^{2} & =0 \\
-U_{1 y}^{1}\left(1+\Delta_{1}-\mu\right)+\lambda-\sigma U_{1 y}^{1}+\xi U_{2 y}^{1} & =0 \\
-U_{2 y}^{2}\left(1-\Delta_{1}+\mu\right)+\lambda+\sigma U_{1 y}^{2}-\xi U_{2 y}^{2} & =0
\end{aligned}
$$

$\lambda$ is the Lagrangian of the profits constraint (15), $\mu$ the respective Lagrangian of the constraint (17), $\sigma$ relates to IC1 (57) and $\xi$ to IC2 (58). Recall the definition $\Phi^{I C}$ as the utility difference that prevails if both IC-constraints are non-binding, IC1 $>0$ and IC2=0 with $\sigma=\xi=0$. Inserting the respective derivatives of the Cobb-Douglas function (4) it follows from (59),(60) and (61), (62):

$$
\begin{aligned}
& U_{1 v}(.) / U_{1 z}(.)=c \quad \rightarrow \quad y_{1}-T_{1}=\frac{(1-\alpha) c v_{1}}{\alpha} \\
& U_{2 v}(.) / U_{2 z}(.)=c \quad \rightarrow \quad y_{2}-T_{2}=\frac{(1-\alpha) c v_{2}}{\alpha}
\end{aligned}
$$


In addition, IC2 $=0$ (see (58)) which applies to the profit constraint (15) as well. This follows from (62), i.e. $\lambda>0$.

From (62), (58) and (15) $\left\{v_{1}^{I C}, v_{2}^{I C}, T_{1}^{I C}, T_{2}^{I C}\right\}$ can be calculated and inserted into the utility functions yielding the differrence $\phi^{I C}=U_{2}^{I C}-U_{1}^{I C}$. If the distributional preferences are in the intervall $\left[\Phi^{I C}, \Phi^{C}\right)$ then we can infer from (60) that $\mu>0$ which assures the result of 1 (a) of proposition 1: The optimal tariff system is such that the optimal difference of wellbeing is equal to the utility difference $\Phi$ regarded as fair. Figure 2 displays this case.

It remains to be shown that strengthening (reducing) $\Phi$ leads to an increase (decrease) $U_{1}^{1}$ $\left(U_{2}^{2}\right)$. This can be inferred from the coverage of fixed costs (see the t1-line in figure 2).

$$
t_{i}=T_{i}-c v_{i}, \quad 1=1,2
$$

Inserting (63) into the Cobb-Douglas function leads to

$$
U_{i}^{*}=\Gamma\left(y_{i}-t_{i}\right), \quad i=1,2
$$

where $\Gamma=(\alpha / c)^{\alpha)}(1-\alpha)^{(1-\alpha}$. Solving for $t_{i}$ yields

$$
t_{i}=y_{i}-\frac{U_{i}^{*}}{\Gamma}, i=1,2
$$

Starting from $\Phi^{C}$ it follows from (67) that a decrease of $\Phi$ cannot be achieved by a simmultaneous increases (decrease) of both utilities with different speeds. In these cases the profit constraint (15) would be violated, since either $t_{1}+t_{2}>F+2 c w_{s}$ or $t_{1}+t_{2}<$ $F+2 c w_{s}$.

The proof of 1. (b) is more extensive. Assume first that $\Phi$ is in the intervall $\left[\Phi^{s b}, \Phi^{I C}\right.$ ) and $\sigma=\xi=0$. Then, by (62) $\mu>0$, but this contradicts to the assumption. Hence one of the two IC-constraints must be binding. We show that the case $\sigma>0$ and $\xi=0$ (case I) cannot be optimal. Instead the case $\sigma=0$ and $\xi>0$ (case II) is optimal. ${ }^{30}$.

Assume, per absurdum, that case I is optimal. From the single crossing condition, the Kuhn-Tucker conditions and the IC-constraints (57) and (58) it follows

$$
\mathcal{U}_{1}^{1}=\mathcal{U}_{1}^{2} \quad \text { and } \quad \mathcal{U}_{2}^{2}>\mathcal{U}_{2}^{1}
$$

where the $\mathcal{U}_{i}^{j}$ are defined in (5). Notice that the symbol $\mathcal{U}$ refers to the utility in case I. Since $\sigma>0$ it follows from (62) that $\mu>\Delta_{1}-1>0$. Therefore we have

$$
\mathcal{U}_{2}^{2}-\mathcal{U}_{1}^{1}=\Phi
$$

\footnotetext{
${ }^{30}$ Hence, case II is depicted in figure 3 .
} 
Inserting (68) into (69) yields

$$
\mathcal{U}_{2}^{2}-\mathcal{U}_{1}^{2}=\Phi
$$

If case II holds instead, then from the IC-constraints (57) and (58) and the Kuhn-Tucker conditions it follows that

$$
U_{1}^{1}>U_{1}^{2} \quad \text { and } \quad U_{2}^{2}=U_{2}^{1}
$$

Since $\Phi \in\left[\Phi^{s b}, \Phi^{I C}\right)$ we also have

$$
U_{2}^{2}-U_{1}^{1}=\Phi
$$

Inserting (71) into (72) yields

$$
U_{2}^{1}-U_{1}^{1}=\Phi
$$

and together with (70)

$$
\mathcal{U}_{2}^{2}-\mathcal{U}_{1}^{2}=\Phi=U_{2}^{1}-U_{1}^{1}
$$

The resulting social welfare for both cases can be determined by inserting the respective utility functions into the SWF (14).

$$
\begin{array}{rr}
\text { case I } & \mathcal{S W P}=\mathcal{U}_{2}^{2}+\mathcal{U}_{2}^{1}-\Delta_{1} \max [0,0] \\
\text { case II } & S W P=U_{2}^{1}+U_{1}^{1}-\Delta_{1} \max [0,0]
\end{array}
$$

Notice that we have utilized the respective IC-constraints.

Since we have assumed, per absurdum, that case I is optimal we must have $\mathcal{S W \mathcal { P }}>S W P$. If we insert (74) into (75) this assumption transforms to

$$
\mathcal{U}_{1}^{2}>U_{1}^{1}
$$

and, by utilizing the respective IC consitions for both cases

$$
\mathcal{U}_{1}^{1}>U_{1}^{1}
$$

To satisfy the profit constraint (15) in case I we must have

$$
\mathcal{U}_{1}^{1}<U_{1}^{C}
$$


Otherwise, i.e. for $\mathcal{U}_{1}^{1}>U_{1}^{C}$ we have

$$
t_{1}<\frac{\left(F+2 c w_{s}\right)}{2}
$$

and hence, by the concavity of the indifference curve $U\left(v_{1}, y_{1}-T_{1}\right)=U_{1}^{1}$, the binding IC1-constraint and $v_{1}<v_{2}$

$$
t_{2}<t_{1}
$$

i. e. costs are not covered. For the same reasons (see figure 3) we must have

$$
U_{1}^{1}>U_{1}^{C}
$$

Otherwise, i.e. $U_{1}^{1}<U_{1}^{C}$ and the binding IC2-constraints together with $v_{1}<v_{2}$ strictly positive profits would occur. But the requirements (79) and (82) contradict the relation (78) that follows from the assumption $\mathcal{S W \mathcal { P }}>S W P$. Hence case I cannot be optimal an the optimal solution is characterized by (61) - (62), the profit constraint (15) and the IC2-constraint (71) with strict equality $(\mathrm{IC} 2=0)$.

The proof of 1.(c) follows from the observation that a seperating optimal tariff solution $\mathcal{T}_{i}^{s b}$ exists. This can inferred from setting $\Phi=0$ (egalitarian solution). From the IC-conditions and the single crossing condition it follows immediately, that in the optimum $U_{2}^{2}>U_{1}^{1}$ Hence, for all $\Phi, 0 \leq \Phi \leq \Phi^{s b}(17)$ cannot be binding $(\mu=0)$.

Part 2 of the proposition 1 follows immediately by inserting the Coase tariff into the utility functions. The resulting allocation $\left\{v_{i}^{C}, T_{i}^{C}\right\}$ satisfies the efficiency properties (63), the profits constraint (15) and, reinserted into the utility functions, leads to utility difference $U_{2}^{2}-U_{1}^{1}$ equal to $\Phi^{C}$, by definition.

To prove part 3 we have to resume the second optimization program which only differs from program 1 with respect to (18). The Kuhn-Tucker conditions are:

$$
\begin{aligned}
U_{1 v}^{1}\left(1-\Delta_{2}+\mu\right)-\lambda c+\sigma U_{1 v}^{1}-\xi U_{2 v}^{1} & =0 \\
U_{2 v}^{2}\left(1+\Delta_{2}-\mu\right)-\lambda c-\sigma U_{1 v}^{2}+\xi U_{2 v}^{2} & =0 \\
-U_{1 y}^{1}\left(1-\Delta_{2}+\mu\right)+\lambda-\sigma U_{1 y}^{1}+\xi U_{2 y}^{1} & =0 \\
-U_{2 y}^{2}\left(1+\Delta_{2}-\mu\right)+\lambda+\sigma U_{1 y}^{2}-\xi U_{2 y}^{2} & =0
\end{aligned}
$$

$\lambda$ is the Lagrangian of the profits constraint (15), $\mu$ the respective Lagrangian of the constraint (17), $\sigma$ relates to IC1 (57) and $\xi$ to IC2 (58). If $\sigma=\xi=0$ it follows from (85) 
that $\mu>0$. Hence, (18) is binding. If we assume, that (18) is not binding we have from the Kuhn-Tucker-conditions $\mu=0$. This requires by (85) that $\sigma>0$ and $\xi=0$ which is case I. But this case is also in the second program not optimal. Since the proof is similar to the first program it is ommitted. Since case I cannot occur and $\sigma=\xi=0$ implies $\mu>0$ , (18) is binding which proves part 3 of the proposition.

\subsection{Second-order conditions to the IC-constraint}

Define $^{31}$

$$
G_{\tilde{z}}(\tilde{z}, z)=U_{v}(v(\tilde{z}), y-T(\tilde{z})) \dot{v}(\tilde{z})-U_{y}(v(\tilde{z}), z-T(\tilde{z})) \dot{T}(\tilde{z})=0
$$

From (87) the optimal message $\tilde{z}$ can be derived. A comparative static analysis yields:

$$
G_{\tilde{z} \tilde{z}}(\tilde{z}, z) \frac{d \tilde{z}}{d z}+G_{\tilde{z} z}(\tilde{z}, z)=0
$$

where $G_{\tilde{z} \tilde{z}}<0$ to secure sufficiency of the first order conditions and $\frac{d \tilde{z}}{d z}=1$ by construction of the incentive compatible functions $v(z), T(z)$. Hence, $G_{\tilde{z} z}(\tilde{z}, z)=-U_{y y} \dot{T}>0$. Since $U_{y y}<0$ it follows that $\dot{T}>0$ and hence, by (87) $\dot{v}>0$.

\subsection{Fairness condition for households with several members}

Inserting the IC-compatible functions $V(z)$ and $T(z)$ into the utility function and differentiating with respect to $z$ yields

$$
\mathcal{V}_{z}(z)=\frac{1}{h(z)}\left[U_{v} \dot{V}(z)-U_{y} \dot{T}(z)-U_{w} V(z) \dot{h}(z) / h(z)+U_{y}\left(1-\frac{(z-T(z)) \dot{h}(y)}{h(z)}\right)\right]
$$

Taking (45) into account it follows:

$$
\frac{\mathcal{V}_{z}(z) z}{\mathcal{V}(z)}=\frac{1}{h(z)}\left[\frac{U_{w} V(z) \dot{h}(z) z}{U h(z)}+\frac{U_{y} z}{U}\left(1-\frac{(z-T(z)) \dot{h}(y)}{h(z)}\right)\right]
$$

Resuming the utility function (26) it is straightforward to determine

$$
U_{y} / U=\frac{(1-\alpha) h}{z-T(z)} \quad \text { and } \quad \frac{U_{w}}{U}=\frac{\alpha h}{V(z)}
$$

If one inserts these expressions into (90), (47) follows immediately if one recalls that $\dot{h}(z) / h(z)=-r / z$.

\footnotetext{
${ }^{31}$ The derivation of IC-conditions for the continuous case are well established in the literature, e.g. Gusnerie and Laffont (1984).
} 


\section{References}

Agthe, D., and R. Billings (1987): Equity, Price Elasticity, and Household Income under Increasing Block Rates for Water; in: American Journal of Economics and Sociology, Vol. 46, p. 273-286.

Biswas, Asit, and Cecilia Tortajada (2005): Water Pricing and Public Private Partnership. International Journal of Water Resources Development.

Boland, J.J., and D. Whittington (2000): The Political Economy of Water Tariff Design in Developing Countries: Increasing Block Tariffs versus Uniform Price with Rebate; in: Dinar, A. (ed.): The Political Economy of Water Pricing Reforms, Oxford University Press for the World Bank, Vol. 13, pp. 215 - 235.

Bolton, G.E., and A. Ockenfels (2000): ERC - A Theory of Equity, Reciprocity, and Competition. in: Amercian Economic Review, Vol. 90, pp. 166-193.

Brown, S., and D. Sibley (1986): The theory of public utility pricing. Cambridge: Cambridge University Press.

Cappelen, A. W. and B. Tungodden (2012): Tax policy and fair inequality. Department of Economics, Norwegian School of Economics. Discussion paper SAM $3 / 2012$.

Coase, R. H. (1946): The Marginal Cost Controversy; in: Economica 13, pp. 169182.

Cowen, P. B., and T. Cowen (1998): Deregulated Private Water Supply: A Policy Option for Developing Countries; in: Cato Journal, Vol. 18, No. 1 (Spring/Summer), pp. 21-41.

J. C. Cox, D. Friedman and S. Gjerstad (2007): A tractable model of reciprocity and fairness- Games and Economic Behavior, Volume 59, Issue 1, April 2007, Pages $17 ? 45$

Dahan, M., and U. Nisan (2007): Unintended Consequences of Increasing Block Tariffs: Pricing Policy in Urban Water; in: Water Resources Research, Vol. 43, No. 3. 
Diakite, D., A. Semenov, and A. Thomas (2009): A proposal for social pricing of water supply in Cote d'Ivoire. Journal of Development Economics, Vol. 88, 258 -268 .

Diamond, Peter, and Emmanuel Saez (2011): The Case for a Progressive Tax: From Basic Research to Policy Recommendations. Journal of Economic Perspectives, Vol. 25, No. 4, 165-90.

Dragulescu, Adrian, and Victor M. Yakovenko (2000): "Evidence for the exponential distribution of income in the USA". Eur. Phys. J. B 20 (21. August): 585-589.

Fehr, E., and K. Schmidt (1999): A Theory of Fairness, Competition, and Cooperation; in: Quarterly Journal of Economics, Vol. 114, pp. 817-868.

Fehr, E., Klein, A. and K. Schmidt (2007): Fairness and Contract Design. Econometrica, Vol. 75, p. 121-154.

Fleurbaey, M. (2008): Fairness, Responsibility, and Welfare. Oxford University Press.

Fershtman, C., Gneezy, U. and J. A. List (2012): Equity Aversion: Social Norms and the Desire to be Ahead, in: American Economic Journal: Microeconomics 2012, 4(4): 131 - 144.

García-Valiñas, Maria A. (2005): Efficiency and Equity in Natural Resources Pricing: A Proposal for Urban Water Distribution Services. Environmental and Resource Economics, Vol. 32, 183-204.

Gaudin, S., R. Griffin, and R. Sickles (2001): Demand Specification for Municipal Water Management: Evaluation of the Stone-Geary Form; in: Land Economics, Vol. 77, No. 3 (August), pp. 399-422.

Goldman, M., H. E. Leland, and D. Sibley (1984): Optimal Nonuniform Prices; in: Review of Economic Studies, Vol. 51, No. 2 (April), pp. 305-19.

Gómez-Lobo, A., and D. Contreras (2003): Water Subsidy Policies: A Comparison of the Chilean and Colombian Schemes. The World Bank Economic Review, Vol. 17, No 3, pp. 391-407.

Gusnerie, R. and J.-J. Laffont (1984): Indirect Public Control of Self-Managed Monopoles. Journal of Comparative Economics, 8, 139 - 158. 
Jones, L. E., A. Schoonbroodt and M. Tertilt (2008): Fertility theories: Can they explain the negative fertility-income relation? NBER Working Paper 14266.

Konow, J. (2000): Fair share: Accountability and cognitive dissonance in allocation decisions, in: American Economic Review, 90 (4), 1072 - 1091.

Mas-Colell, A., M. Whinston, and J. Green (1995): Microeconomic Theory (1st. ed.); Oxford, New York: Oxford University Press.

Menard, Claude, and George Clarke (2000a): A Transitory Regime - Water Supply in Conakry, Guinea. World Bank Policy Research Working Paper 2362.

Menard, Claude, and George Clarke (2000b): Reforming the Water Supply in Abidjan, Côte d'Ivoire - Mild Reform in a Turbulent Environment. World Bank Policy Research Working Paper 2377.

Martinez-Espineira, Roberto, and Céline Nauges (2004): Is all Domestic Water Consumption Sensitive to Price Control? Applied Economics, Vol. 36, 1697-1703.

Mirrlees, J. A. (1971): An Exploration in the Theory of Optimum Income Taxation; in: Review of Economic Studies, Vol. 38, No. 114 (April), pp. 175-208.

Mirrlees, J. A., (1976): Optimal Tax Theory : A Synthesis; in: Journal of Public Economics, Vol. 6, No. 4 (November), pp. 327-358.

Rey-Biel, P. (2008): Inequity Aversion and Team Incentives. Scand. J. of Economics 110(2), pp. 297-320.

Roemer, J. E. (1998): Equality of Opportunity. Cambridge, MA: Harvard University Press.

Sharkey, W. W., and D. S. Sibley (1993): Optimal Non-linear Pricing with Regulatory Preference over Customer Type; in: Journal of Public Economics, Vol. 50, No. 2, pp. 197-229.

Shirley, Mary (2002): Thirsting for Efficiency. Institutional Reform in Urban Water. World Bank.

Spiller, Pablo (2005): Urban Water Sector Reform. Washington, D.C., Interamerican Development Bank.

Whittington, D. (2003): Municipal Water Pricing and Tariff Design: A Reform Agenda for South Asia; in: Water Policy, Vol. 5, pp.61-76. 
Wilson, Robert (1992): Nonlinear Pricing. Oxford (UK), Oxford University Press. Wolfstetter, E. (1999): Topics in Microeconomics. Industrial Organization, Auctions and Incentives; Cambridge (UK), Cambridge University Press. 